\title{
TGF $\beta$ Imprinting During Activation Promotes Natural Killer Cell Cytokine Hypersecretion
}

\author{
Jennifer A. Foltz ${ }^{1}{ }^{(\mathbb{D}}$, Jena E. Moseman ${ }^{1}$, Aarohi Thakkar ${ }^{1}$, Nitin Chakravarti ${ }^{1}$ and \\ Dean A. Lee ${ }^{1,2, *}$ \\ 1 Nationwide Children's Hospital, Center for Childhood Cancer and Blood Diseases, Columbus, OH 43205, \\ USA; Jennifer.A.Foltz@wustl.edu (J.A.F.); Jena.Moseman@nationwidechildrens.org (J.E.M.); \\ Aarohi.Thakkar@nationwidechildrens.org (A.T.); Nitin.Chakravarti@nationwidechildrens.org (N.C.) \\ 2 Department of Pediatrics, The Ohio State University, Columbus, OH 43210, USA \\ * Correspondence: Dean.Lee@nationwidechildrens.org; Tel.: +1-614-355-3594
}

Received: 18 October 2018; Accepted: 31 October 2018; Published: 5 November 2018

\begin{abstract}
Transforming growth factor-beta (TGF $\beta$ ) is a potent immunosuppressive cytokine that inhibits the anti-tumor responses of NK cells and T cells. However, the stimulation of natural killer (NK) cells with pro-inflammatory cytokines decreases NK cell sensitivity to TGF $\beta$. Herein, we sought to determine if TGF $\beta$ imprinting (TGF $\beta$ i) during NK cell activation and expansion would decrease NK cell sensitivity to TGF $\beta$ suppression. To this end, we demonstrate that the activation of NK cells during chronic IL-2 stimulation and TGF $\beta i$ potently induces NK cell hypersecretion of interferon-gamma (IFN $\gamma$ ) and tumor necrosis factor-alpha (TNF $\alpha$ ) in response to tumor targets which persists for at least one month in vitro after the removal of TGF $\beta$. TGF $\beta$ i NK cell cytokine hypersecretion is induced following both cytokine and tumor activation. Further, TGF $\beta$ i NK cells have a marked suppression of SMAD3 and T-bet which is associated with altered chromatin accessibility. In contrast to their heightened cytokine secretion, TGF $\beta i$ NK cells downregulate several activating receptors, granzyme and perforin, and upregulate TRAIL, leading to cell-line-specific alterations in cytotoxicity. These findings may impact our understanding of how TGF $\beta$ affects NK cell development and anti-tumor function.
\end{abstract}

Keywords: natural killer cells; TGF $\beta$; IFN $\gamma$; cell therapy; IL-2; cytokines; immune therapy; tumor microenvironment

\section{Introduction}

Natural Killer (NK) cells are part of the innate immune system and are critical in the immune surveillance of both virally infected cells and cancerous cells. NK cells can induce target cell death through multiple mechanisms including granzyme/perforin release, secretion of tumor necrosis factor-alpha (TNF $\alpha)$, and receptor-mediated cytotoxicity by TNF-related apoptosis inducing ligand (TRAIL) and FasL [1,2]. NK cells are activated to kill malignant cells using activating and inhibitory receptors that engage with stress and self-ligands expressed on malignant cells [3,4]. These receptors include the natural cytotoxicity receptors- NKp46, NKp44, and NKp30, along with NKG2D, DNAX Accessory Molecule-1 (DNAM-1), Fc gamma receptor III (CD16), and TRAIL, and the family of activating and inhibitory killer immunoglobulin receptors (KIR). NK cells are commonly distinguished by the intensity of their surface expression of CD56. CD56 ${ }^{\text {bright }} \mathrm{NK}$ cells largely lack the expression of CD16. Functionally, CD56 ${ }^{\text {bright }}$ NK cells are potent cytokine producers, but are weakly cytotoxic unless pre-activated [5]. On the other hand, CD56 ${ }^{\mathrm{dim}} \mathrm{NK}$ cells express high levels of CD16. CD56 ${ }^{\mathrm{dim}}$ NK cells are less potent cytokine producers, but are highly cytotoxic. Further, CD56 ${ }^{\text {bright }}$ NK cells are 
predominantly located within tissues, whereas CD $56^{\mathrm{dim}} \mathrm{NK}$ cells make up the majority of peripheral blood NK cells $[6,7]$.

NK cell activation is regulated not only by the expression of ligands on target cells, but also by cytokine priming. NK cell function can be augmented by stimulation with interleukin (IL)-2, IL-12, IL-15, IL-18, and IL-21. IL-15 and IL-2 promote NK cell cytotoxicity, survival, and proliferation through the activation of STAT signaling, PI3K, and MAPK pathways [8,9]. IL-21, which primarily signals through STAT3, promotes NK cell proliferation and NKG2D expression [10,11]. Importantly, simultaneous stimulation of NK cells with multiple cytokines has distinct effects on NK cell function that differs from stimulation by the same cytokines separately. For example, simultaneous stimulation with IL-12, IL-15, and IL-18 generates cytokine-induced memory-like NK cells with significantly increased interferon-gamma (IFN $\gamma$ ) secretion following recall weeks later, whereas stimulation with IL-12, IL-15, or IL-18 individually does not generate cytokine-induced memory-like NK cells [12].

In addition, NK cell function is regulated by anti-inflammatory cytokines such as IL-10, IL-37, and transforming growth factor beta (TGF $\beta)[13,14]$. TGF $\beta$ is a potent suppressor of the NK cell anti-tumor response and is present at elevated levels in the tumor microenvironment [15-17]. TGF $\beta$ activates SMAD2 and SMAD3 downstream of TGF $\beta$ RI/II causing suppression of NK cell IFN $\gamma$ production by downregulating the transcription factors T-bet and E4BP4 [18-20]. Further, TGF $\beta$ inhibits NK cell cytotoxicity by decreasing granzyme and perforin, and downregulates several activating receptors including NKG2D, NKp30, DNAM-1, TRAIL, and CD16, thereby inhibiting NK cell recognition of malignant cells expressing their cognate ligands [21-29]. Importantly, TGF $\beta$ has an acute effect on NK cell cytokine production and cytotoxicity, with the inhibition of function observed in primary NK cells following only a few hours of TGF $\beta$ exposure. The TGF $\beta$ suppression of NK cell function can be partially abrogated by the stimulation of NK cells with IL-12/IL-15/IL-18 or with ALT-803, an IL-15 superagonist/IL-15R $\alpha$ Sushi-Fc fusion complex [19,30].

Since NK cells may be chronically exposed to TGF $\beta$ during tumor infiltration, we sought to determine if activation of NK cells in the presence of TGF $\beta$ such as in the tumor microenvironment would decrease NK cell sensitivity to TGF $\beta$. To this end, we found that the activation of NK cells by either tumor stimuli or cytokines in the presence of TGF $\beta$ induces potent NK cell anti-tumor IFN $\gamma$ and $\mathrm{TNF} \alpha$ secretion and alterations in NK cell cytotoxicity, corresponding to the downregulation of T-bet and SMAD3 expression.

\section{Results}

\subsection{Chronic Stimulation by TGF $\beta$ during NK Cell Expansion and Activation Generates NK Cells with Increased Cytokine Secretion}

To investigate the effect of chronic TGF $\beta$ stimulation during NK cell propagation and activation, NK cells were isolated from healthy peripheral blood and TGF $\beta$ imprinted (TGF $\beta$ i) for 14 days by culturing with both IL-2 and $10 \mathrm{ng} / \mathrm{mL}$ TGF $\beta$ (a concentration previously reported to activate TGF $\beta$ signaling and suppress NK cell function) in combination with a weekly stimulation with irradiated K562 feeder cells expressing membrane-bound IL-21 (mbIL21) and 4-1BBL, which are known to induce robust NK cell proliferation and activation, resulting in a median $\sim 2,500$-fold expansion in 14 days [11]. TGF $\beta$ had a minimal impact on K562mbIL-21.41BBL induced NK cell proliferation, with NK cell expansion ranging from 465 to 3200 -fold and an average viability that was greater than 96\% (Figure 1A).

Since TGF $\beta$ is a potent inhibitor of IFN $\gamma$ and $\operatorname{TNF} \alpha$ secretion, we next sought to determine cytokine secretion of donor-matched control and TGF $\beta$ i NK cells at the end of the 14 days of expansion. NK cells were rested overnight without TGF $\beta$ (baseline) and after acute TGF $\beta$ treatment (rested overnight in TGF $\beta$ ). TGF $\beta$ i significantly increased IFN $\gamma$ secretion against all tumor targets tested (Figure 1B), and significantly increased TNF $\alpha$ secretion against all tumor targets except CHLA-255 (Figure 1C). When TGF $\beta$ was included in the cytotoxicity assay, it significantly suppressed the IFN $\gamma$ secretion of control NK cells against MG63, and of TGF $\beta$ i NK cells against MG63 and DAOY, but not 
CHLA-255 (Figure 1B). However, CHLA-255 stimulated less cytokine secretion than DAOY and MG63 from both the control and TGF $\beta$ i NK cells. Neither TGF $\beta$ i NK nor control NK cell TNF $\alpha$ secretion was significantly inhibited by acute TGF $\beta$ treatment against any cell line tested (Figure $1 \mathrm{C}$ ). Tumors cultured alone in IL-2 or IL-2 plus TGF $\beta$ did not produce any detectable IFN $\gamma$ or TNF $\alpha$.

A



B



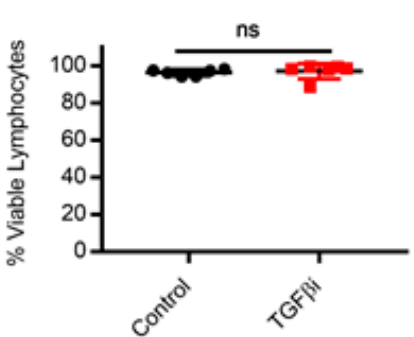
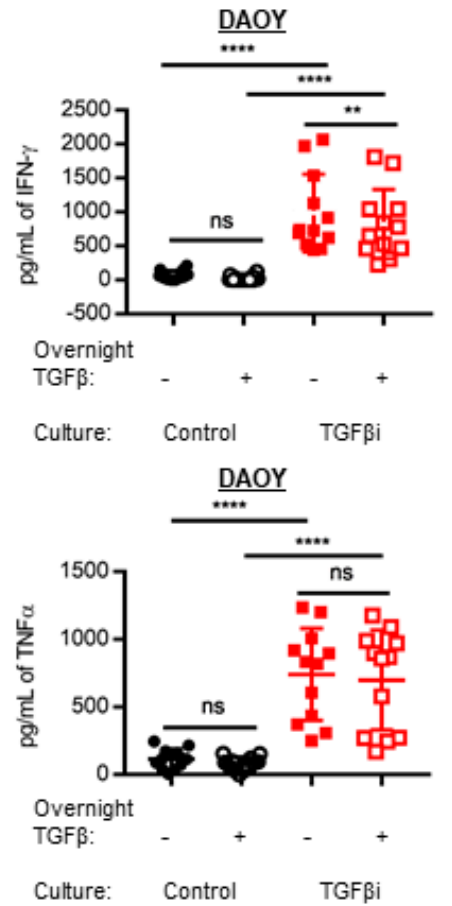

PHA

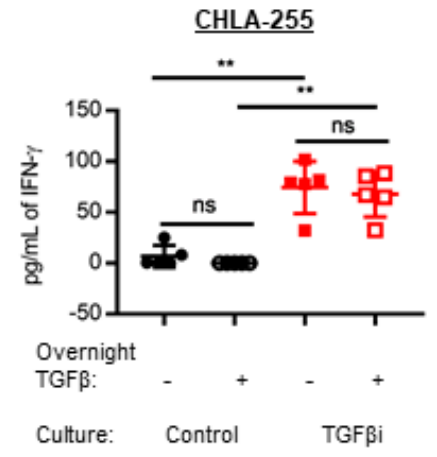

CHLA-255



D


DAOY

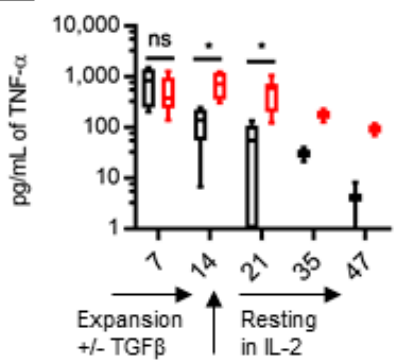

Figure 1. The chronic stimulation by transforming growth factor-beta (TGF $\beta$ ) during natural killer 
(NK) cell expansion and activation generates NK cells with increased cytokine secretion. NK cells were cultured for 14 days in $50 \mathrm{IU} / \mathrm{mL}$ IL-2 or $50 \mathrm{IU} / \mathrm{mL}$ IL-2 plus $10 \mathrm{ng} / \mathrm{mL}$ TGF $\beta$ (TGF $\beta$ ) with a weekly stimulation with K562 mbIL-21 feeder cells. (A) NK cell proliferation was compared by determining the fold change of control and TGF 3 i total NK $\left(\mathrm{CD} 3^{-} / \mathrm{CD}^{2} 6^{+}\right.$and CD3 $\left.{ }^{-} / \mathrm{CD} 16^{+}\right)$cells at Day 14 and the viability of total cells was determined using Tonbo Viability dye. (B) After 14 days of expansion, NK cells were rested overnight with $50 \mathrm{IU} / \mathrm{mL}$ IL-2 (- TGF $\beta$, baseline) or $50 \mathrm{IU} / \mathrm{mL}$ IL-2 plus $10 \mathrm{ng} / \mathrm{mL}$ TGF $\beta$ (+ TGF $\beta$, acute TGF $\beta$ treatment). NK cells were then co-cultured with tumor targets for $3 \mathrm{~h}$ in fresh media (under identical cytokine conditions as used in the overnight rest) and supernatants were collected to measure interferon-gamma (IFN $\gamma$ ) and tumor necrosis factor-alpha $(\mathrm{TNF} \alpha)$ cytokine secretion using Cytometric Bead Array analysis. Individual data points are depicted for MG63 (osteosarcoma) (IFN $\gamma: n=12, \operatorname{TNF} \alpha: n=9$ ), DAOY (medulloblastoma) $(n=12)$, and CHLA-255 (neuroblastoma) $(n=5)$. (D) The control and TGF $\beta$ i NK cells were stimulated with 10 $\mu \mathrm{g} / \mathrm{mL}$ of PHA at 2 e $6 \mathrm{NK}$ cells/mL for $4 \mathrm{~h}$ and cytokine secretion was measured by cytometric bead array (CBA) or a MACSPlex Cytokine $12 \mathrm{Kit}$. Individual data points depicted. Lines and bars represent Mean \pm SD. (E) TGF $\beta$ i and control NK cell anti-tumor cytokine secretion following overnight treatment in fresh media with $50 \mathrm{IU} / \mathrm{mL}$ IL-2 was assessed against DAOY at Day 7 and Day 14 of expansion, and after removal from expansion conditions at Day 21, 35 and $47+/-1$ day as described for Figure 1B,C. (Day $7 n=5$, Day 14 and $21 n=6$, Day 35 and 47,n=2)). Median with min to max whiskers depicted. Control in black, TGF $\beta i$ in red. Statistical differences were determined by paired $t$-test $(\mathbf{A}, \mathbf{D}, \mathbf{E})$ and two-way repeated measures ANOVA with Holm-Sidak's multiple comparisons test for all others. ${ }^{*} p \leq 0.05,{ }^{* *} p \leq 0.01,{ }^{* * *} p \leq 0.001,{ }^{* * * *} p \leq 0.0001$. See also Figures S1 and S2.

Next, we wanted to determine if this effect was due to an increase in the percentage of cytokine-producing NK cells or an increase in the amount of cytokine produced by each NK cell. To this end, we found that TGFßi significantly increased the percentage of cytokine-producing NK cells in response to tumor targets (Figure S1). Further, of the cytokine-producing NK cells, there was an increased intensity of IFN $\gamma$ and TNF $\alpha$ (gMFI) in TGF $\beta$ i NK cells (Figure S2), suggesting that TGF $\beta i$ increases both the percentage of NK cells secreting cytokine and the amount of cytokine produced by the NK cells.

To determine if TGF $\beta$ i effected the secretion of cytokines other than IFN $\gamma$ and TNF $\alpha$ irrespective of the tumor target, TGF $\beta$ i and control NK cells were stimulated with phytohaemagglutinin (PHA) for $4 \mathrm{~h}$. Following PHA stimulation, we found that TGF $\beta$ i NK cells produced significantly more IFN $\gamma$ and $\mathrm{TNF} \alpha$, and granulocyte-macrophage colony-stimulating factor (GM-CSF), but the TGF $\beta$ i NK cells were not different from control NK cells in IFN $\alpha$, IL-2, IL-4, IL-5, IL-10, IL-12, or IL-17A secretion. We were unable to detect any secretion of IL-6 or IL-9 in any of the donors tested (Figure 1D). Therefore, TGF $\beta \mathrm{i}$ selectively modifies NK cell cytokine secretion.

We next sought to determine the onset of TGF $\beta$ i NK cell cytokine hypersecretion and the duration of cytokine hypersecretion following their removal from the imprinting conditions. NK cells were expanded for 14 days with K562mbIL-21.41BBL and subsequently removed from their expansion conditions and cultured in IL-2 alone. The secretion of IFN $\gamma$ and TNF $\alpha$ by NK cells in response to tumor target stimulation (DAOY) following overnight treatment with IL-2 was measured in supernatants at Day 7, 14, and 1 week, 3 weeks, and 1 month (33 days) post-expansion. TGF 3 i NK cells demonstrated the onset of cytokine hypersecretion after 14 days of culture with K562.mbIL-21.41BBL and TGF $\beta$ (Figure 1E). Following removal from TGF $\beta$, TGF $\beta$ i NK cells maintained their significantly increased cytokine hypersecretion for 33 days following TGF $\beta$ stimulation, whereas the control NK cells exhibited a rapid decline in IFN $\gamma$ secretion as early as day 21 of culture (1 week post-expansion). Thus, chronic stimulation with K562mbIL-21.41BBL feeder cells and TGF $\beta$ reprograms NK cells to become pro-inflammatory cytokine secretors that persist after the removal of IL-21 and TGF $\beta$ signals. 


\subsection{NK Cell Activation is Required for TGF $\beta$ Induced Cytokine Hypersecretion}

Since the feeder cells utilized for NK cell propagation in Figure 1 express membrane-bound IL-21 and IL-21 is known to modify TGF $\beta$ signaling in T-cells, we sought to determine if membrane-bound IL-21 is required for TGF $\beta$ i by using K562 that express membrane-bound IL-15 instead of membrane-bound IL-21. Membrane-bound IL-15 expressing K562 also induced increased IFN $\gamma$ and TNF $\alpha$ secretion by TGF $\beta$ i NK cells at both the baseline and in the presence of acute overnight TGF $\beta$ treatment compared to the control NK cells (Figure 2A). Thus, membrane-bound IL-21 is not required for TGF $\beta$ i. Under these conditions, TNF $\alpha$ secretion, but not IFN $\gamma$ secretion, was inhibited by acute TGF $\beta$ treatment in both the control and TGF $\beta$ i NK cells.

A

K562 mblL-15.4-1BBL



MG63

B


$\underline{\mathrm{MG} 63}$

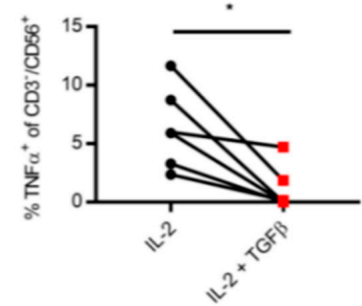

\section{Parental K562}

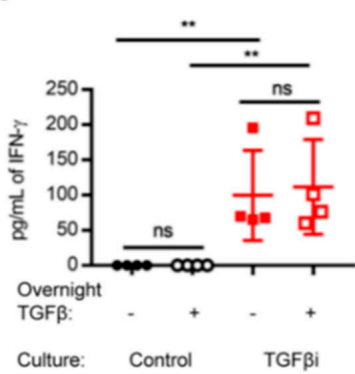

MG63
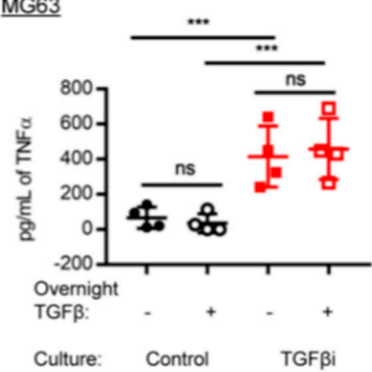

D

IL-12/IL-15/IL-18 Overnight Stimulation
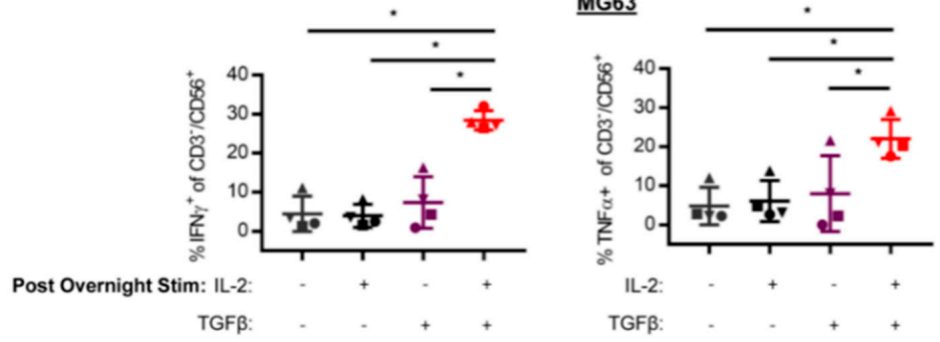

Figure 2. NK cell activation is required for TGF $\beta$ induced cytokine hypersecretion. NK cells were cultured with IL-2 alone or IL-2 plus $10 \mathrm{ng} / \mathrm{mL}$ TGFb and (A) K562mbIL-15 (IFN $\gamma: n=4$, TNF $\alpha: n=3$ ) or (B) no feeder cell $(n=6)$, or $($ C) parental K562 $(n=4)$ for 7-14 days. Following culture, anti-tumor cytokine secretion or production by CBA or intracellular flow cytometry was assessed against an MG63 
tumor target. (D) NK cells were stimulated overnight with $10 \mathrm{ng} / \mathrm{mL}$ IL-12, $50 \mathrm{ng} / \mathrm{mL}$ IL-15, and $50 \mathrm{ng} / \mathrm{mL}$ IL-18 plus or minus IL-2 and TGF $\beta$. Following overnight stimulation, the NK cells were cultured with $1 \mathrm{ng} / \mathrm{mL}$ IL-15 plus or minus IL-2 and TGF $\beta$. After 7-14 days of culture, anti-tumor IFN $\gamma$ and TNF $\alpha$ production in response to MG63 was measured by intracellular flow cytometry $(n=4)$. Percent anti-tumor IFN $\gamma+$ and TNF $\alpha+$ NK cells normalized to no target depicted for (B) and (D). Individual data points depicted for all. Lines and bars represent Mean $\pm \mathrm{SD}$. Statistical differences were determined by paired t-test for 2B and two-way repeated measures ANOVA with Holm-Sidak's multiple comparisons test for all other graphs. ${ }^{*} p \leq 0.05,{ }^{* *} p \leq 0.01,{ }^{* * *} p \leq 0.001,{ }^{* * * *} p \leq 0.0001$. See also Figure S3.

Next, we wanted to determine whether K562 feeder cells are required for TGF $\beta$ i NK cell cytokine hypersecretion. To this end, primary NK cells were cultured with IL-2 alone or IL-2 plus TGF $\beta$. In contrast to the effect of TGF $\beta$ in combination with the K562 feeder cells, IL-2 plus TGF $\beta$ alone did not enhance the anti-tumor IFN $\gamma$ and TNF $\alpha$ production, in agreement with what has been previously reported (Figure 2B).

Since both K562mbIL-15 and K562mbIL-21 feeder cells express 4-1BBL, we wanted to determine if 4-1BBL was required for TGF $\beta$ i NK cell cytokine hypersecretion. To determine this, primary NK cells were cultured with irradiated parental K562 in combination with IL-2 and TGF $\beta$, as previously described. NK cells cultured with IL-2 plus TGF $\beta$ and parental K562 also exhibited significantly increased IFN $\gamma$ (Figure 2C) and TNF $\alpha$ (Figure 2C) secretion against MG63 compared to the NK cells expanded on parental K562 without TGF $\beta$. Thus, the expression of membrane-bound IL-21, IL-15, or 4-1BBL on the feeder cells are not required for TGF $\beta$ induced cytokine hyperproduction; however, NK cells cultured with parental K562 produced less IFN $\gamma$ and TNF $\alpha$ in response to MG63 than NK cells cultured with K562mbIL-21, suggesting that membrane-bound IL-21 and 4-1BBL increase the overall cytokine production (Figure S3).

Next, we wanted to determine if cytokine hyperproduction could be induced by TGF $\beta$ in the absence of tumor stimulation. IL-12/IL-15/IL-18 has previously been reported to promote the activation of NK cells in the absence of tumor stimulation $[12,19]$. Thus, primary NK cells were stimulated overnight with IL-12/IL-15/IL-18 plus or minus IL-2 and TGF $\beta$. Following overnight stimulation, the NK cells were washed with saline and continued in culture with IL-15 alone, IL-15 plus TGF $\beta$, IL-15 plus IL-2, or IL-15 plus both IL-2 and TGF $\beta$. IL-2 was used in addition to IL-15 since IL-15 plus TGF $\beta$ was not sufficient to induce TGF $\beta$ i NK cells. A significant increase in IFN $\gamma$ and TNF $\alpha$ was only observed when IL-2, IL-15, and TGF $\beta$ were present (Figure 2D) after the initial cytokine activation, suggesting that an initial activation signal (either cytokine or tumor-induced) and a prolonged culture with IL-2 are required for TGF $\beta$ to induce cytokine hyperproduction.

\subsection{TGFßi generates NK Cells with Increased Degranulation but Transiently Impairs Cytotoxicity}

Since TGF $\beta$ potently inhibits NK cell anti-tumor cytotoxicity, we assessed the cytolytic capacity of TGF $\beta$ i NK cells. TGF $\beta i$ NK cells had significantly increased anti-tumor degranulation as measured by their surface expression of CD107a against MG63, HOS (osteosarcoma), and DAOY. Degranulation was significantly increased at both the baseline and following overnight acute TGF $\beta$ treatment (Figure 3A). Further, although acute overnight TGF $\beta$ treatment inhibited the degranulation of control NK cells against HOS, TGF $\beta$ i NK cells were not inhibited by the acute TGF $\beta$ treatment. 
A

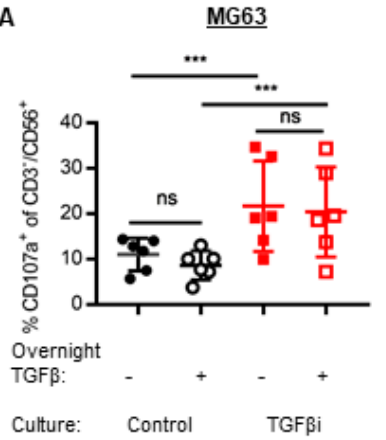

Culture: Control TGFi

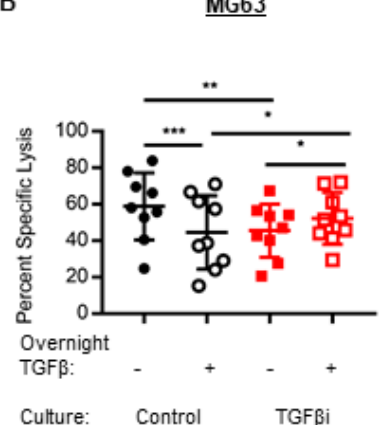

CHLA-255

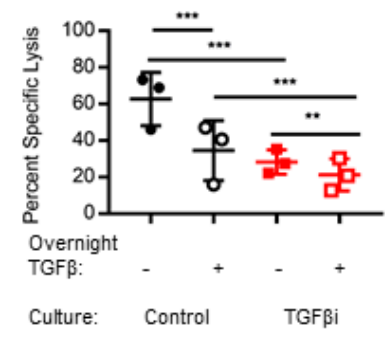

$\mathrm{C}$

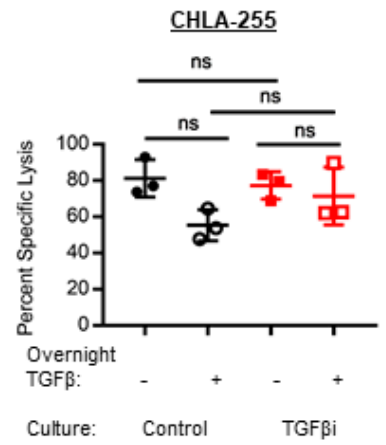

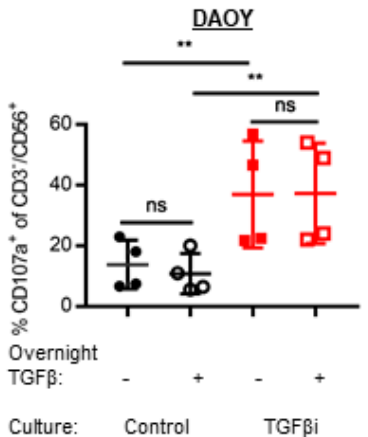

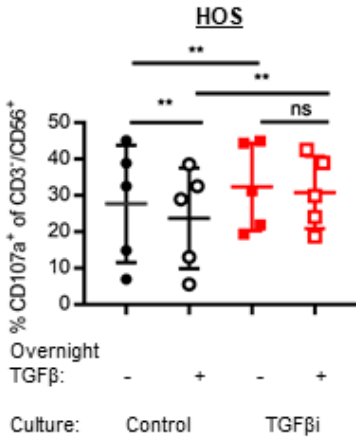

$\underline{\text { DAOY }}$


1 week Removal from TGF $\beta$ $\underline{\text { MG63 }}$



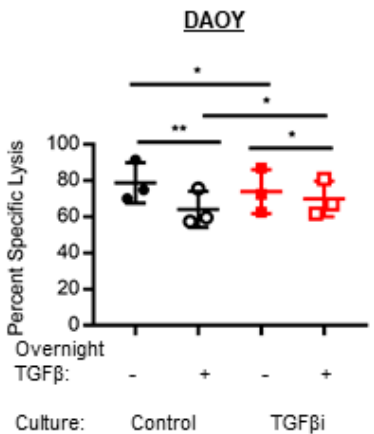

Figure 3. TGF $\beta$ i generates NK cells with increased degranulation but transiently impairs cytotoxicity. (A) Control and TGF $\beta$ i NK cells from K562mbIL-21 expansions were rested overnight in IL-2 or IL-2 + TGF $\beta$ and subsequently stimulated with tumor targets for $3 \mathrm{~h}$ (MG63, $n=6$; DAOY, $n=4$; HOS, $n=5$ ) and assessed for degranulation by CD107a. \%CD107a ${ }^{+} \mathrm{NK}$ cells are corrected for no target controls. (B) The control and TGF $\beta$ i NK cell cytotoxicity was measured using a 4-h calcein-release cytotoxicity assay, following overnight treatment in IL-2 alone or IL-2 plus TGF $\beta$. (MG63, $n=9$; DAOY, $n=3$; HOS, $n=5$; CHLA-255, $n=3$ ). (C) TGF $\beta$ i NK cells were removed from TGF $\beta$ for 7 days ( \pm 1 day) and cytotoxicity against CHLA-255, MG63, and DAOY following overnight treatment with IL-2 or IL-2 plus TGF $\beta$ was measured using a calcein-release assay $(n=3)$. Individual data points depicted for all. Lines and bars represent Mean \pm SD. Statistical differences were determined by two-way repeated measures ANOVA with Holm-Sidak's multiple comparisons test. ${ }^{*} p \leq 0.05,{ }^{* *} p \leq 0.01,{ }^{* * *} p \leq 0.001$, $* * * * p \leq 0.0001$. 
However, since degranulation does not always positively correlate with tumor cell death, we measured the ability of TGF $\beta$ i NK cells to induce tumor cell death using a 4-h calcein release cytotoxicity assay. Against DAOY, the TGF $\beta$ i NK cells had similar cytotoxicity as control NK cells at both the baseline and following acute TGF $\beta$ treatment (Figure 3B). Further, neither the control nor TGF $\beta$ i NK cytotoxicity was suppressed by acute TGF $\beta$ treatment. However, against the osteosarcoma cell lines MG63 and HOS, TGF $\beta$ i NK cells were significantly inhibited at baseline, but not following the acute TGF $\beta$ treatment. In addition, TGF $\beta$ i NK cells were not suppressed by acute TGF $\beta$; whereas the control NK cell cytotoxicity against MG63 was inhibited by acute TGF $\beta$ treatment. The cytotoxicity of TGF $\beta$ i NK cells against CHLA-255 was markedly inhibited at both baseline and following acute TGF $\beta$ treatment. Further, both control and TGF $\beta$ i NK cells had suppressed cytotoxicity by acute TGF $\beta$ treatment. Therefore, the effect of TGF $\beta$ i on NK cell cytotoxicity is largely cell-line dependent.

Next, we sought to determine if TGF $\beta$ i NK cells would recover their cytotoxicity following their removal from TGF $\beta$ for 1 week. To this end, TGF $\beta$ i NK cell cytotoxicity was no longer suppressed against CHLA-255 and MG63, suggesting that a short-term removal from TGF $\beta$ is an effective strategy to recover cytolytic function in TGF $\beta$ i NK cells (Figure 3C). However, TGF $\beta$ i NK cell cytotoxicity was slightly but significantly inhibited following their removal from TGF $\beta$ against DAOY at baseline (without overnight TGF $\beta$ treatment); whereas, TGF $\beta$ i NK cell cytotoxicity with overnight TGF $\beta$ treatment was slightly but significantly enhanced compared to the control NK cells.

\subsection{TGF Bi Remodels NK Cell Receptor Expression}

Next, we wanted to determine if TGFßi remodels the NK cell receptor repertoire. To this end, we performed flow cytometry on several NK cell receptors previously reported to be inhibited by acute TGF $\beta$ treatment at Day 7,14, and 21, and confirmed these changes at the transcriptional level at Day 14 using RNA-seq [23-25,28,31,32]. We found that TGF $\beta$ i significantly suppressed NKG2D, CD16, and NKp30 expression and increased FasL and NKG2A expression as early as Day 7 of expansion (Figure 4A and Figure S4A). Conversely, DNAM-1, TRAIL, and CD57 were not significantly affected until after 14 days of expansion. NKp30, DNAM-1, and FCGR3A/CD16 protein expressions correlated with decreased mRNA expression at Day 14 (Figure 4B). We found slight changes in TRAIL and CD16 chromatin accessibility at Day 14 (Figure 4C).

Following one week of removal from TGF $\beta$ (Day 21), DNAM-1, FasL and TRAIL expression recovered to similar levels of the control NK cells, whereas CD16 and NKp30 remain suppressed (Figure S4B). It is important to note that the impact of TGF $\beta$ i on TRAIL expression was highly donor-dependent as 4/6 donors phenotyped at Day 7 did not have changes in TRAIL expression at any time point, despite significant changes in 10/14 donors measured at Day 14. Intriguingly, NKG2D was expressed at significantly higher levels (gMFI) than the control NK cells following one-week removal from TGF $\beta$. Therefore, TGF $\beta$ i modifies NK cell activating receptor expression. 
A
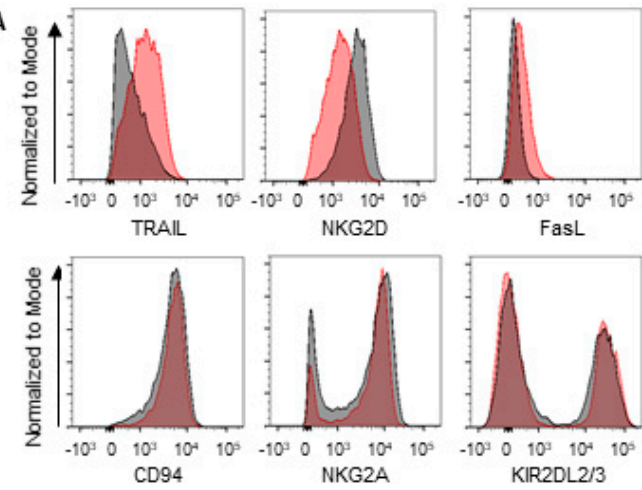

FasL

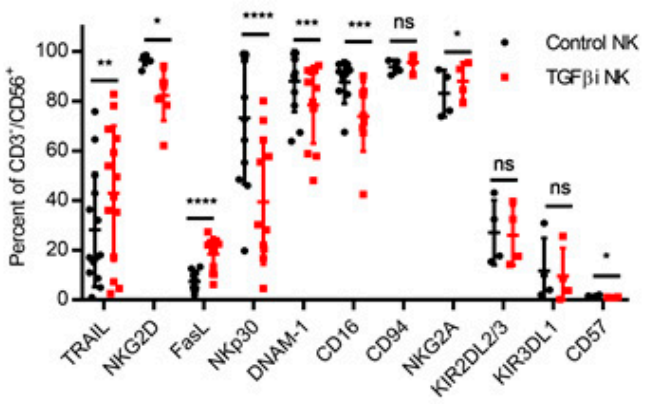

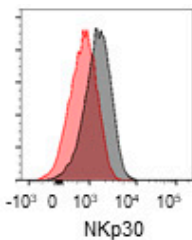
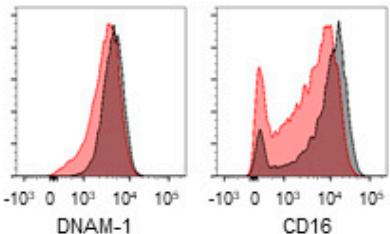

CD16
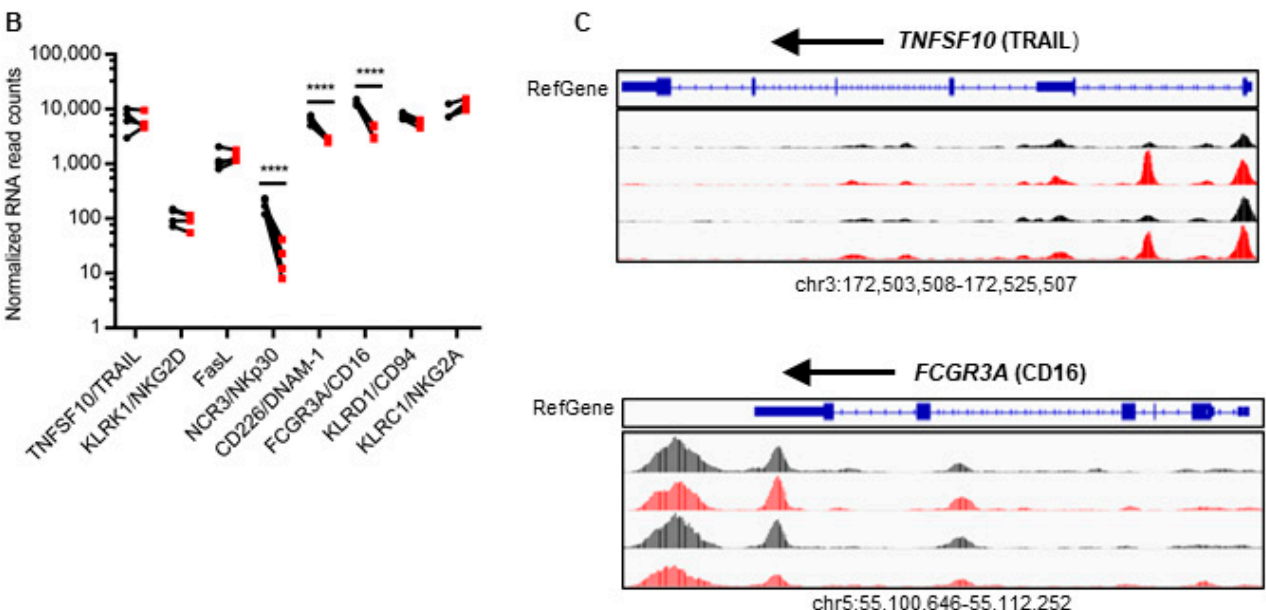

Figure 4. TGF $\beta$ i remodels K562mbIL-21 expanded NK cell receptor expression. (A) Cell surface protein expression on the control and TGF $\beta$ i NK cells was measured using flow cytometry. Geometric median fluorescent intensity (gMFI) normalized to viability only stained NK cells are shown. Flow data from one representative donor is depicted. Control in black, TGF $\beta$ i in red. (B) mRNA expression of NK cell receptors was assessed by RNA-seq $(n=4)$. (C) Chromatin accessibility of TNSF10 and FCGR3A was determined at Day 14 using ATAC-seq. Control in black, TGF $\beta i$ in red. Individual Data points depicted. Lines and bars represent Mean $\pm \mathrm{SD}$. Statistical differences were determined by paired $t$-test and DESeq2 for RNA-seq. ${ }^{*} p \leq 0.05,{ }^{* *} p \leq 0.01,{ }^{* * *} p \leq 0.001,{ }^{* * * *} p \leq 0.0001$. See also Figures $\mathrm{S} 4$ and S5.

\subsection{TGF Bi Decreases Granzyme A and Perforin Expression.}

Since NK cell granzyme and perforin content can influence NK cell cytotoxicity and the calcein-release cytotoxicity assay is known to predominantly measure granzyme-perforin cytotoxicity, we measured granzyme and perforin expression to determine if their expression could explain the decreased cytotoxicity of TGF $\beta$ i NK cells against MG63, HOS, and CHLA-255. TGF $\beta$ i NK cells had a significant reduction in granzyme A and perforin protein (Figure 5A) and mRNA (Figure 5B) (MFI), but no significant change in the percentage of NK cells positive for granzyme A or perforin 
(Figure 5A). Surprisingly, no significant change was observed in granzyme B mRNA or protein. Next, we wanted to determine if the decrease in granzyme A and perforin expression was correlated with changes in chromatin accessibility. However, there was no significant change in the chromatin accessibility of granzyme A, granzyme B, or perforin in the TGF $\beta$ i NK cells (Figure 5C and Figure S5). The decrease in cytotoxicity of TGF $\beta$ i NK cells against some cell lines may also be due to defects in the granzyme-perforin release.

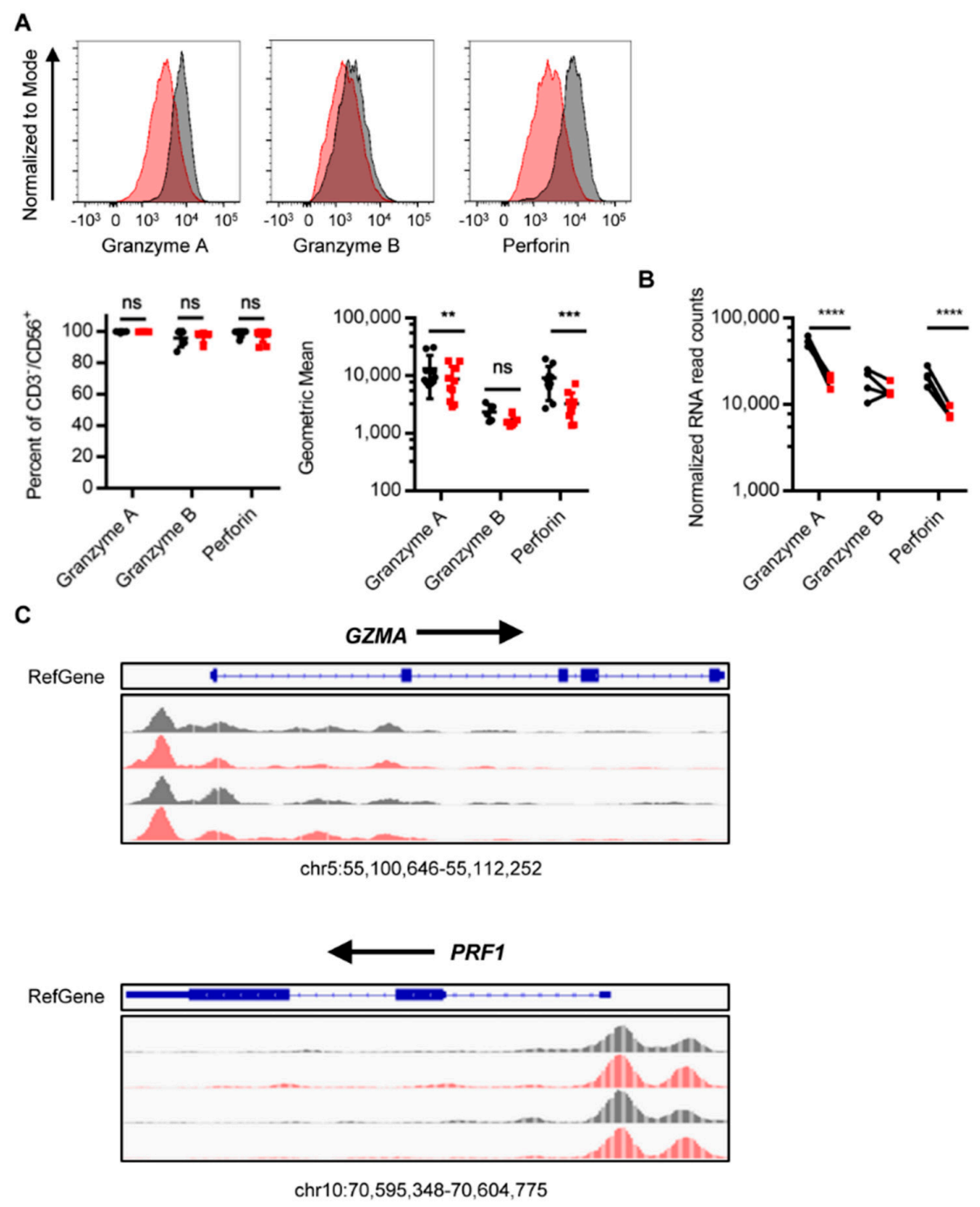

Figure 5. TGF $\beta$ i decreases granzyme A and perforin expression. (A) Granzyme and perforin protein expression in TGF $\beta$ i NK cells were measured by flow cytometry. Percent positive NK cells and relative expression (gMFI) were depicted. Granzyme A and perforin $(n=10)$, granzyme B $(n=5)$. A representative flow plot is depicted. (B) mRNA ( $n=4$ for RNA) of granzymes and perforin was measured using RNA-seq. ( $n=4$ for RNA). (C) Chromatin accessibility of GZMA and PRF1 loci as measured by ATAC-seq. Control in black, TGF $\beta$ i in red. Data are Mean $\pm \mathrm{SD}$. Statistical differences were determined by paired $t$-test and RNA-seq by DESeq2. ${ }^{*} p \leq 0.05,{ }^{* *} p \leq 0.01,{ }^{* * *} p \leq 0.001$, $* * * * p \leq 0.0001$. See also Figure S5.

\subsection{TGF $\beta$ Imprinting Modifies NK Cell IFN $\gamma$ Regulation}

Since TGF $\beta$ i NK cells have remarkably increased anti-tumor IFN $\gamma$ secretion, we hypothesized that TGF $\beta$ imprinting modified the transcription factors important for IFN $\gamma$ secretion. To this end, we performed a genome-wide unbiased screening using RNA-seq to determine the expression levels for a broad range of transcription factors. TGF 3 i NK cells had significantly increased JUN and NFKB1 
and significantly decreased IKBKE, NFKBIZ, NFKB2, NFATC1, NFATC3, FOS, SMAD3, and TBX21 (Figure 6A,B). No significant change was observed in $Y Y 1, I R F 1$, IRF2, NFAT5, NFATC2, NFATC2IP, CREB1, ATF1, ATF2, ETS1, RUNX3, GATA3, NFIL3, or SMAD2 (Figure 6B). To further validate that the downregulation of $S M A D 3$ was a unique alteration in the TGF $\beta$ pathway induced by TGF $\beta$, we performed qPCR of 92 genes in the TGF $\beta$ pathway and verified their significance against our RNA-seq data. Using this approach, SMAD3 was 1 of 3 genes significantly altered in the TGF $\beta$ pathway, with TGFBR3 and SMAD6 also being significantly changed, demonstrating that TGF $\beta \mathrm{i}$ induces selective changes in the TGF $\beta$ pathway. Since SMAD3, TBX21 (T-bet), and NFIL3 (E4BP4) have been demonstrated to be targets of TGF $\beta$ signaling that suppress NK cell IFN $\gamma$ production, we further validated these findings at the protein level. Concordant with the mRNA data, we found that SMAD3 and T-bet were decreased at the protein level while E4BP4 was not significantly changed (Figure 6C,D). In addition, SMAD3 chromatin accessibility was decreased in TGF $\beta$ i NK cells suggesting epigenetic remodulation as the mechanism of SMAD3 downregulation. In contrast, TBX21 (T-bet) chromatin was not remodeled suggesting other mechanisms of mRNA downregulation (Figure 6C,D).

A

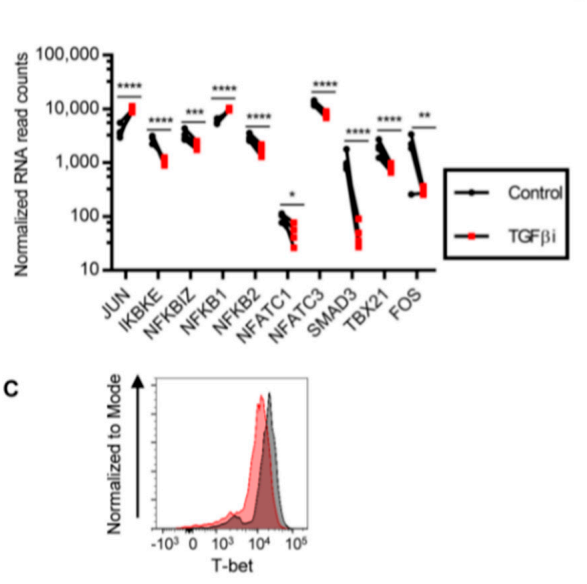

B

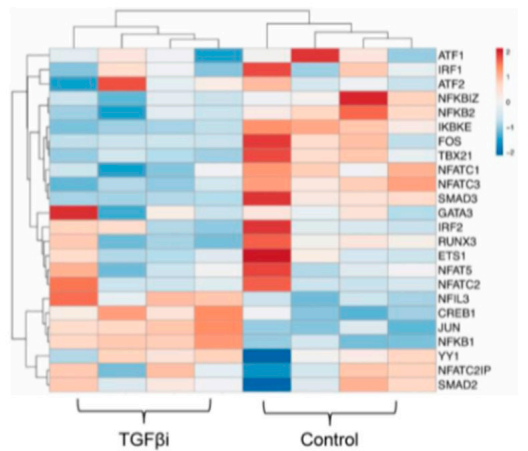

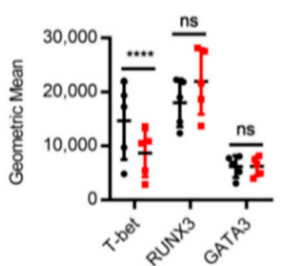

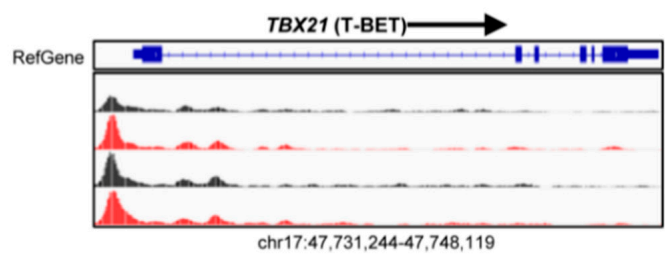

D



Figure 6. TGF $\beta$ imprinting modifies the NK cell IFN $\gamma$ regulation. See also Figure S4. (A) RNA expression of significantly changed IFN $\gamma$ regulatory genes as assessed using RNA-seq (all $n=4$ ). (B) Expression of IFN $\gamma$ regulatory genes shown using Clustvis. (C) T-bet protein expression level (gMFI) was assessed using flow cytometry. Representative donor depicted $(n=5)$. Chromatin accessibility of TBX21 (T-bet) was determined using ATAC-seq. Control in black, TGF $\beta$ i in red. (D) SMAD3 and E4BP4 $(n=4)$ protein expressions were measured by western blot. Chromatin accessibility of SMAD3 was measured by ATAC-seq. See also Figure S6. Statistical differences were determined using DESeq2 for RNA-seq and paired $t$-test for flow cytometry. ${ }^{*} p \leq 0.05,{ }^{* *} p \leq 0.01,{ }^{* * *} p \leq 0.001,{ }^{* * * *} p \leq 0.0001$. 
Next, we sought to determine the onset and duration of SMAD3 and T-bet suppression following TGF $\beta$ i. To this end, we assessed the expression of SMAD3 and T-bet in the control and TGF $\beta$ i NK cells at Day 7 and Day 14 of the expansion and 1 week following their removal from TGF $\beta$ at Day 21 (Figure S4C). SMAD3 suppression was observed at Day 7, and the expression of SMAD3 was recovering at Day 21. Similarly, the T-bet expression also recovered by Day 21. Thus, in contrast to previous studies, our results suggest that when chronically exposed in the presence of IL-2, TGF $\beta$ does not inhibit the E4BP4 expression and that TGF $\beta$ i NK cell IFN $\gamma$ hypersecretion does not correlate with T-bet expression.

\section{Discussion}

Numerous studies have demonstrated that TGF $\beta$ is a potent suppressor of NK cell anti-tumor activity by inhibiting cytotoxicity, cytokine secretion, and NK cell proliferation. Herein, our data demonstrate for the first time that the activation of NK cells in the presence of IL-2 and TGF $\beta$ drives NK cells into a pro-inflammatory phenotype with hypersecretion of IFN $\gamma$, TNF $\alpha$, and GM-CSF. This cytokine hypersecretion persists for at least one month following TGF $\beta$ imprinting and corresponds to changes in several IFN $\gamma$ regulatory genes including JUN, T-bet, and SMAD3 [19]. Further, TGF $\beta$ i NK cells have altered cytotoxicity that is cell-line dependent (increased in some and decreased in others), likely due to decreased granzyme A and perforin expression. Therefore, the chronic co-stimulation of NK cells with IL-2 and TGF $\beta$ during cytokine and tumor activation represents a novel setting in which TGF $\beta$ induces pro-inflammatory NK cells.

Our data demonstrate that chronic TGF $\beta$ imprinting in conjunction with activation and IL-2 has opposite effects of acute TGF $\beta$ exposure ( $6 \mathrm{~h}$ to 3 days), driving NK cells to produce more IFN $\gamma$ and TNF $\alpha$ upon tumor target and PHA stimulation than NK cells that were not TGF $\beta$ imprinted $[18,19,21,31]$. Further, TGF $\beta$ i selectively modulated NK cell cytokine secretion increasing IFN $\gamma$, TNF $\alpha$, and GM-CSF secretion, but not IFN $\alpha$, IL-2, IL-4, IL-5, IL-10, IL-12, or IL-17A. Interestingly, TGF $\beta$ i NK cell cytokine hypersecretion could be induced by both feeder cell stimulation and, in the absence of feeder cell stimulation, by using IL-2 plus IL-12/IL-15/IL-18 with TGF $\beta$ supplementation. Thus, TGF $\beta$ i NK cell cytokine hypersecretion develops independently of the receptor-ligand interactions between NK cells and K562 feeder cells, and likely represents a common activation pathway shared between cytokine and tumor-stimulated NK cells. In addition, cytokine secretion was not dependent upon the receptor-ligand interactions between tumor targets and NK cells, rather, the increased cytokine secretion following PHA stimulation suggests that TGF $\beta i$ cytokine hypersecretion likely reflects transcriptional and translational changes. Furthermore, these changes persist following the recovery of SMAD3, T-bet, and NKG2D expression.

Whether TGF $\beta$ i NK cells develop naturally in vivo remains to be determined. There is potential for TGF $\beta i$ to occur during chronic activation in the body such as in the tumor microenvironment or during wound healing. However, since TGF $\beta$ i requires extended TGF $\beta$ exposure, NK cells must remain in these pro-inflammatory microenvironments for several days to induce TGF $\beta$ i. Despite following the phenotypic changes of TGF $\beta$ i NK cells during expansion and following the removal from TGF $\beta$, we were unable to identify a cell-surface marker that correlated with the acquisition of cytokine hypersecretion (Day 14 in K562mbIL-21 expanded NK cells). The identification of a cell-surface marker of TGF $\beta i$ to identify these NK cells in vivo is an important area of future investigation.

A positive effect of TGF $\beta$ on NK cell function was suggested in a recent study demonstrating that TGF $\beta$ signaling increases NK cell anti-tumor activity, as SMAD4 ${ }^{-/-}$murine NK cells had decreased cytotoxicity [33]. In addition, TGF $\beta$ is necessary for the development of salivary gland ILC1s and was able to convert NK cells into ILC1s $[34,35]$. Further, TGF $\beta$ promotes survival of salivary gland ILC1s and some T-cell subsets, raising the question of whether TGF $\beta$ is similarly promoting the survival of TGF $\beta$ i NK cells [34]. This may be enhancing cytokine and tumor activation such as by IL-2 and K562 feeder cells, thereby alleviating cytokine-induced death [34,36-38]. Similar to our TGF $\beta$ i NK cells, TRAIL expression was upregulated on the salivary gland ILC1s by TGF $\beta$. However, ILC1s were 
not potent IFN $\gamma$ producers and conversion of NK cells into ILC1s was associated with decreased anti-tumor activity [34,35]. In contrast, TGF $\beta$ i NK cells maintain anti-tumor cytotoxicity against some cell lines (DAOY) and produce more IFN $\gamma$ than NK cells cultured without TGF $\beta$, suggesting that TGF $\beta$ in this system does not convert NK cells into ILC1s.

In agreement with previous studies, both acute TGF $\beta$-treated NK cells and chronic TGF $\beta$ i NK cells had decreased cytotoxicity against some cell lines [21,25,26,31,35]. Despite decreased activating receptor expression, degranulation by TGF $\beta$ i NK cells was not inhibited, suggesting no defect in the activation by tumor targets; however, degranulation did not correlate with cytotoxicity. This effect is likely due to the decreased granule content in TGF $\beta$ i NK cells, as the effectiveness of degranulation in mediating cell death is largely dependent upon the granzyme/perforin content [39]. The cell-line dependent effect of TGF $\beta$ i on NK cell cytotoxicity likely represents different pathways of cytotoxicity which will be of particular interest for future investigations. Further, it is intriguing that TGF $\beta$ i NK cells recover their cytotoxicity against CHLA-255 and MG63 following their removal from TGF $\beta$ while maintaining TGF $\beta$-induced pro-inflammatory cytokine secretion, suggesting that TGF $\beta$ has effects on cytotoxicity that are not epigenetic. Cytotoxicity recovery may be due to the recovery of NKG2D and DNAM-1 expression following their removal from TGF $\beta$.

TGFßi NK cells have a differential expression of several transcription factors known to be important for NK cell IFN $\gamma$ secretion. Previously, it was reported that both T-bet and E4BP4 were suppressed by TGF $\beta$, leading to a decrease in IFN $\gamma$ secretion. Similarly, we found that T-bet decreased following TGF $\beta$ in our TGF $\beta$ i NK cells; however, surprisingly, TGF $\beta$ i NK cells produced significantly more IFN $\gamma$. Thus, the residual T-bet expression may be able to promote IFN $\gamma$ expression more efficiently in the absence of SMAD3, or other transcription factors may promote IFN $\gamma$ secretion in this setting. TGF 3 i NK cells had similar levels of E4BP4, which may be due to the loss of SMAD3 in TGF $\beta$ i NK cells since SMAD3 has been reported to suppress E4BP4 expression [20]. In contrast, TGF $\beta$ can suppress T-bet expression through SMAD2 in the absence of SMAD3. Thus, SMAD2 may be downregulating T-bet expression in TGF $\beta$ i NK cells [19]. We found increased Jun and NFKB1 which are known to be important in activation-induced transcription of IFN $\gamma$, suggesting that they may be upregulating IFN $\gamma$ transcription in TGF $\beta$ i NK cells [40-42].

Based on their enhanced cytokine production and their TRAIL and FasL expression, TGF $\beta \mathrm{i}$ NK cells may be an effective novel therapy in certain solid tumors. TGF $\beta$ i NK may have increased efficacy in vivo in settings where IFN $\gamma$ can activate macrophages and CD8 T cells to stimulate adaptive immunity. Additionally, IFN $\gamma$ itself can sensitize tumors to NK cell cytotoxicity [43-48]. In addition, TNF $\alpha$ can directly kill tumors expressing TNFRs and works in concert with IFN $\gamma$ to inhibit cancer cell proliferation [47]. Further, FasL and TRAIL may be preferentially used by NK cells during in vivo cytotoxicity compared to in vitro cytotoxicity $[49,50]$. Thus, future studies are needed to determine the therapeutic potential of TGF $\beta$ i NK.

\section{Conclusions}

In summary, TGF $\beta$ 's effect on NK cells is context-dependent, such that chronic TGF $\beta$ in the presence of IL-2 and activating signals generates NK cells that hypersecrete IFN $\gamma, \mathrm{TNF} \alpha$, and GM-CSF that persists after their removal from TGF $\beta$. In contrast, TGF $\beta$ i transiently impairs in vitro cytotoxicity, which recovers rapidly following their removal from TGF $\beta$. The data reported here delineates a novel effect where TGF $\beta$ can induce pro-inflammatory NK cells.

\section{Materials and Methods}

\subsection{Cell Lines and Culture Conditions}

Experiments using discarded anonymized buffy coats from normal human red blood cell (RBC) donations from the American Red Cross (Columbus, OH, USA) were IRB exempt. Blood was processed using Ficoll Plus (GE Healthcare; 17-1440-02), as described previously. Human NK cells were purified 
with a RosetteSep Human NK Cell Enrichment Cocktail (Stem Cell Technologies, 15065, Vancouver, BC, Canada) as described in Reference [51]. NK cell purity was greater than $85 \%$, with less than $5 \%$ contaminating T-cells.

Cell line identity was authenticated using STR fingerprinting (Idexx Biosciences, Columbia, MO, USA) and routinely tested for mycoplasma contamination. DAOY was cultured in MEM with $1 \%$ Non-essential amino acids, $1 \%$ glutamax, $1 \%$ P/S and 10\% FBS. MG63 and HOS were cultured in DMEM with $1 \% \mathrm{P} / \mathrm{S}$ and $10 \%$ FBS. CHLA-255 was cultured in 20\% FBS in IMDM with $1 \%$ glutamax, $1 \%$ ITS, and $1 \% \mathrm{P} / \mathrm{S}$. Cells were dissociated for cytotoxicity assays using an enzyme-free Cell Dissociation Buffer, Hank's Based (ThermoFisher Scientific, 13150016, Carlsbad, CA, USA). NK cells were cultured in RPMI 1640 media plus Glutamax, 10\% FBS, and P/S. K562 feeder cells were derived by transducing K562, a chronic myelogenous leukemia cell line, with human 4-1BBL and membrane-bound human IL-21, as previously described [11].

Purified primary human NK cells were stimulated at Day 0 1:2 with 100 Gy irradiated K562 mbIL-21, K562mbIL-15, or parental K562 as indicated and 1:1 at Day 7. Control expanded NK cells were supplemented with $50 \mathrm{IU} / \mathrm{mL}$ recombinant human IL-2, and TGF $\beta$ i expanded NK cells received $50 \mathrm{IU} / \mathrm{mL}$ IL-2 (Prometheus, 22mmu NDC 65483-0116-07, San Diego, CA, USA) plus $10 \mathrm{ng} / \mathrm{mL}$ TGF $\beta$ (Biolegend, 580706, San Diego, CA, USA) every 2-3 days. Day 14 NK cell purity was $\geq 90 \%$ $\mathrm{CD}^{-} / \mathrm{CD} 6^{+}$, and $\mathrm{CD}^{-} / \mathrm{CD}^{+} 6^{+}$cells. NK Cell Expansion was calculated based on the percentage of $\mathrm{CD}^{-} / \mathrm{CD} 6^{+} / \mathrm{CD} 6^{+/-}$cells within the lymphocyte gate as determined by FSC/SSC.

For measuring the persistence of TGF $\beta$ i NK cell function, donor-matched NK cells were expanded as described above using K562 mbIL-21 feeder cells. After 14 days, the NK cells were rested in 50 IU / $\mathrm{mL}$ IL-2 alone for 7-33 days and IFN $\gamma$ and TNF $\alpha$ secretion was measured at a 5:1 (NK: tumor) ratio following $3 \mathrm{~h}$ co-culture with DAOY using BD Cytometric Bead Array (details of this method are described below).

For NK cell stimulation with IL-12, IL-15, and IL-18, primary NK cells were stimulated overnight with $10 \mathrm{ng} / \mathrm{mL}$ IL-12 (Biolegend, 573002), $50 \mathrm{ng} / \mathrm{mL}$ IL-15 (Biolegend, 570302) and $50 \mathrm{ng} / \mathrm{mL}$ IL-18 (Biolegend, 592102) as described and rested in $1 \mathrm{ng} / \mathrm{mL}$ IL-15 for 7-14 days following overnight stimulation with IL-12, IL-15, and IL-18 [12]. For determining the effect of IL-2 and TGF $\beta$ on cytokine production, the NK cells were treated as described but with the addition of IL-2 and/or TGF $\beta$ as indicated in the overnight stimulation with IL-12, IL-15, and IL-18, and along with $1 \mathrm{ng} / \mathrm{mL}$ IL-15 for 7-14 days. To measure the cytokine production, the NK cells were rested in $1 \mathrm{ng} / \mathrm{mL}$ IL-15 only overnight and throughout the assay and co-cultured with MG63 at a 5:1 ratio or equal numbers of NK cells only as a no target control and intracellular flow staining was conducted as described below.

\subsection{Flow Cytometry}

The staining of human NK cells was conducted as described previously in blocking buffer of $50 \%$ FBS/PBS. Transcription factors were stained using the Transcription Factor Buffer Kit (BD Biosciences, 562725, San Diego, CA, USA). All other intracellular flow cytometry studies were done using the BD Cytofix/Cytoperm Fixation/Permeabilization Kit with GolgiStop (BD Biosciences, 554715). Antibodies for the following proteins were used to assess NK phenotype and function: CD3 PeCy7 / APC-H7 (BD Biosciences, clone SK7), CD56 FITC/BB515/BV421 (BD Biosciences, Clone NCAM16.2; clone B159, clone R19-760)), NKG2D Pe-CF594/BV510 (BD Biosciences, clone 1D11), TRAIL PE/APC/BV421 (BD Biosciences, clone RIK-2), FasL PE (BD Biosciences, clone NOK-1), NKp30 PE/Alexa Fluor 647 (BD Biosciences, Cat\#: 558407, 558408), NKp30 PE-Vio615 (Miltenyi, Cat\#: 130-112-434, Bergisch Gladbach, Germany), CD94 APC (Miltenyi, Cat\#: 130-098-976), CD57 Pe-Vio615 (Miltenyi, Cat\#: 130-111-815), KIR3DL1 BV421 (BD Biosciences, clone DX9), KIR2DL2/3 Pe-Vio770 (Miltenyi, Cat\#: 130-099-892), NKG2A APC (Miltenyi, Cat\#: 130-098-812), granzyme A APC (Miltenyi, Cat\#: 130-099-780), granzyme B BV510 (BD Biosciences, clone GB11), perforin BV421 (BD Biosciences, clone $\delta \mathrm{G} 9$ ), DNAM-1 BV711 (BD Biosciences, clone DX11), CD107a BV510 (BD Biosciences, clone H4A3), IFN $\gamma$ APC (Biolegend, clone 4S.B3), TNF $\alpha$ BV421 (Biolegend, clone Mab11), CD16 
PE/APC (BD Biosciences, clone B73.1; Miltenyi, Cat\#: 130-106-705)), T-bet APC (Biolegend, clone 4B10), GATA3 BV421 (Biolegend, clone 16E10A23), RUNX3 PE (BD Pharmingen, R3-5G4, San Diego, CA, USA), and Tonbo Ghost Dye 510/710/780 (Tonbo Biosciences, San Diego, CA, USA). For determining the percent of NK cells expressing proteins, cells were gated on Live/CD3 ${ }^{-} / \mathrm{CD}^{5} 6^{+}$for all analysis.

To determine degranulation by CD107a expression and intracellular cytokine production in response to tumors, NK cells were rested overnight in fresh media containing either $50 \mathrm{IU} / \mathrm{mL}$ of IL-2 (baseline) or $50 \mathrm{IU} / \mathrm{mL}$ IL-2 and $10 \mathrm{ng} / \mathrm{mL}$ TGF $\beta$. Following overnight cytokine stimulation, the NK cells were resuspended in fresh media with the same cytokines as used in the overnight cytokine stimulation. The NK cells were co-cultured in a 96-well round-bottom plate with tumor cells (5:1 E:T ratio) or no target for a control in $200 \mu \mathrm{L}$ media as described for cytotoxicity assays. One $\mu \mathrm{L}$ of monensin was added to each sample along with CD107a at the beginning of the assay. Plates were spun down at $100 \mathrm{~g} \times 2 \mathrm{~min}$ to promote cell-cell contact and placed in a $37^{\circ} \mathrm{C}$ incubator for $3 \mathrm{~h}$ (NK cells expanded with $\mathrm{K} 562 \mathrm{mbIL}-21, \mathrm{~K} 562 \mathrm{mbIL}-15$, and $\mathrm{K} 562$ parental) or $6 \mathrm{~h}$ (cytokine only stimulations). After incubation, the media were removed and staining began for cell surface and intracellular proteins as detailed. To determine tumor-specific NK cell production, CD107a, IFN $\gamma$, and TNF $\alpha$ percent of NK cells and gMFI were normalized to NK cells with no target.

\subsection{Cytotoxicity Assay}

Calcein (Invitrogen, C3099, Carlsbad, CA, USA) assays were conducted as described previously. NK cells were prepared for cytotoxicity assays as described for intracellular functional flow. NK cells and tumors were cultured at a 5:1 Effector:Target ratio.

\subsection{Cytokine Secretion}

To determine the NK cell release of IFN $\gamma$ and TNF $\alpha$, NK cells were cultured as described for intracellular functional flow cytometry with the exception of the monensin and CD107a antibody. After $3 \mathrm{~h}$ co-culture with tumor targets or $4 \mathrm{~h}$ stimulation with $10 \mu \mathrm{g} / \mathrm{mL}$ PHA, supernatants were collected and frozen at $-75^{\circ} \mathrm{C}$ until use. On the day of the assay, the supernatants were thawed and $50 \mu \mathrm{L}$ of undiluted supernatant was used according to the manufacturer's instructions for the BD CBA Soluble Protein Master Kit (BD Biosciences, Cat\#: 558265) and IFN $\gamma$ and TNF $\alpha$ Flex Set (BD Biosciences, Cat: 558269, 560112) or MACSPlex Cytokine 12 Kit (Miltenyi, Cat: 130-099-169). The analytes were acquired on a BD LSR II or a MACSQuant. The geometric mean for each analyte was determined in Flow Jo v. 10.1 and unknown samples were interpolated using a standard curve with $\mathrm{R}^{2} \geq 0.9$ from the known standards for BD LSR II acquired samples. Analysis of MACSQuant acquired analytes was done using MACSQuantify software (version 2.8, Bergisch Gladbach, Germany). This software uses average APC median values of MACSPlex Standards and calculates the cytokine concentration in each sample.

\section{5. $q P C R$}

RNA from fresh, never frozen, Day 14 K562mbIL-21 expanded human NK cells was isolated using the Qiagen MiniPrep kit. cDNA was made using the high throughput cDNA kit (Applied Biosystems, \#4368814, Carlsbad, CA, USA). PCR for the TGF $\beta$ pathway was done using a Taqman Fast PCR Mastermix and Human Fast 96-well TGF $\beta$ Pathway Array (ThermoFisher, 4418742, Pleasanton, CA, USA) on an Applied Biosystems 7900HT.

\subsection{RNA-Seq Sample Preparation and Sequencing}

Total RNA was prepared from K562 mbIL-21 expanded control and TGF $\beta$ i NK cells as per manufacturer's instructions using the Total RNA Purification Plus Kit (Norgen Biotek, Thorold, ON, Canada) and the resulting total RNA was quantified in a Nanodrop ND-1000 spectrophotometer, and checked for purity and integrity in a Bioanalyzer-2100 device (Agilent Technologies Inc., Santa Clara, CA, USA) and submitted to the genomics core at the Nationwide Children's Hospital for 
sequencing. Libraries were prepared using the TruSeq RNA Sample Preparation Kit (Illumina Inc., San Diego, CA, USA) according to the protocols recommended by the manufacturer. The quality of the libraries were determined via Agilent 4200 Tapestation using a High Sensitivity D1000 ScreenTape Assay kit and quantified by KAPA qPCR (KAPA BioSystems, Cape Town, South Africa). Approximately 60-80 million paired-end $150 \mathrm{bp}$ sequence reads per library were generated using the Illumina HiSeq4000 platform.

\subsection{ATAC-seq}

K562mbIL-21 expanded control and TGF $\beta$ i NK cells were counted, resuspended in growth media containing 5\% DMSO and then aliquoted in cryovials containing 100,000 viable cells/vial. Cells were frozen at a slow cooling rate and stored at $-80{ }^{\circ} \mathrm{C}$ prior to processing for ATAC-seq. ATAC-seq was performed as described [52]. DNA libraries were sequenced using Illumina HiSeq 2500 at 50 bp paired end reads.

\subsection{Western Blotting}

Whole cell extracts were isolated from K562mbIL-21 expanded NK cells using a RIPA Lysis Buffer (Pierce Biotechnology, Rockford, IL, USA) supplemented with protease and phosphatase inhibitors (Thermo Scientific). The concentration of the isolated proteins was determined using a BSA Protein Assay kit (Bio-Rad, Santa Rosa, CA, USA). Fifteen-twenty micrograms of the protein were separated on SDS-PAGE or 4-12\% NuPage Bis-Tris gel (Thermo Scientific) and electrophoretically transferred to PVDF membranes. Membranes were then incubated with the primary antibodies against the proteins of interest Smad3 (Clone C67H9), NFIL3 (clone D5K8O), T-bet (clone D6N8B), or $\beta$-actin (clone 8H10D10) (all Cell Signaling, Cambridge, MA, USA) and were detected with HRP-conjugated appropriate secondary antibodies either anti-rabbit IgG, HRP-linked (Cell Signaling, Cat: 7074S) or anti-mouse IgG, HRP-linked (Cell Signaling, Cat: 7076S) and visualized with the ECL Western blotting substrate (Pierce Biotechnology, Rockford, IL, USA), according to the provided protocol.

\subsection{Statistical Analysis}

Statistical analyses were performed as described in each figure legend using GraphPad Prism 6.0 or 7.0 (La Jolla, CA, USA). $p$ Values less than 0.05 were considered significant. The heatmap and unsupervised clustering were analyzed using Clustvis [53].

\section{Patents}

D.A.L., J.A.F. and J.E.M. have submitted a US patent on intellectual property relevant to this manuscript.

Supplementary Materials: The following are available online at http:/ /www.mdpi.com/2072-6694/10/11/423/ s1, Figure S1: TGF $\beta$ i NK cells have increased anti-tumor IFN $\gamma+$ and TNF $\alpha+$ NK cells; Figure S2: TGF $\beta$ imprinting increases intensity of IFN $\gamma$ and TNF $\alpha$ production; Figure S3. Differential IFN $\gamma$ and TNF $\alpha$ secretion induced by parental K562 versus K562mbIL-21 feeder cell expansion; Figure S4. Related to Figures 4 and 6 . Phenotypic analysis of TGF $\beta$ i NK cells at Day 7, 14, \& 21; Figure S5: ATAC-seq results for TGF $\beta$ imprinted NK cell phenotype; Figure S6: ATAC-seq results for TGF $\beta$ imprinted NK cell transcription factors.

Author Contributions: Conceptualization, J.A.F., J.E.M., N.C. and D.A.L.; Formal analysis, J.A.F., A.T., N.C. and D.A.L.; Funding acquisition, J.A.F. and D.A.L.; Investigation, J.A.F., J.E.M. and N.C.; Methodology, J.A.F., J.E.M., A.T., N.C. and D.A.L.; Supervision, D.A.L.; Validation, J.A.F. and J.E.M.; Visualization, J.A.F. and N.C.; Writing-original draft, J.A.F., N.C. and D.A.L.; Writing-review \& editing, J.A.F., J.E.M., A.T., N.C. and D.A.L.

Funding: This research was funded by CancerFree Kids and Peer Reviewed Cancer Research Program (PRCRP) Translational Team Science Award CA160461 from the Department of Defense.

Conflicts of Interest: DAL serves/has served as a consultant for Courier Therapeutics, Obsidian Therapeutics, Intellia Therapeutics, Merck Research Laboratories, and Miltenyi Biotec, and has equity and leadership position in CytoSen Therapeutics. DAL, JAF, and JEM have submitted a US patent on intellectual property relevant to this manuscript. The funders had no role in the design of the study; in the collection, analyses, or interpretation 
of data; in the writing of the manuscript, and in the decision to publish the results. There are no other conflicts of interest.

\section{References}

1. Zamai, L.; Ahmad, M.; Bennett, I.M.; Azzoni, L.; Alnemri, E.S.; Perussia, B. Natural killer (NK) cell-mediated cytotoxicity: Differential use of trail and fas ligand by immature and mature primary human NK cells. J. Exp. Med. 1998, 188, 2375-2380. [CrossRef] [PubMed]

2. Kayagaki, N.; Yamaguchi, N.; Nakayama, M.; Takeda, K.; Akiba, H.; Tsutsui, H.; Okamura, H.; Nakanishi, K.; Okumura, K.; Yagita, H. Expression and function of tnf-related apoptosis-inducing ligand on murine activated NK cells. J. Immunol. 1999, 163, 1906-1913. [PubMed]

3. Ljunggren, H.G.; Karre, K. In search of the "missing self": Mhc molecules and NK cell recognition. Immunol. Today 1990, 11, 237-244. [CrossRef]

4. Pegram, H.J.; Andrews, D.M.; Smyth, M.J.; Darcy, P.K.; Kershaw, M.H. Activating and inhibitory receptors of natural killer cells. Immunol. Cell Biol. 2011, 89, 216-224. [CrossRef] [PubMed]

5. Wagner, J.A.; Rosario, M.; Romee, R.; Berrien-Elliott, M.M.; Schneider, S.E.; Leong, J.W.; Sullivan, R.P.; Jewell, B.A.; Becker-Hapak, M.; Schappe, T.; et al. Cd56bright NK cells exhibit potent antitumor responses following il-15 priming. J. Clin. Investig. 2017, 127, 4042-4058. [CrossRef] [PubMed]

6. Cooper, M.A.; Fehniger, T.A.; Turner, S.C.; Chen, K.S.; Ghaheri, B.A.; Ghayur, T.; Carson, W.E.; Caligiuri, M.A. Human natural killer cells: A unique innate immunoregulatory role for the cd56(bright) subset. Blood 2001, 97, 3146-3151. [CrossRef] [PubMed]

7. Poli, A.; Michel, T.; Theresine, M.; Andres, E.; Hentges, F.; Zimmer, J. Cd56bright natural killer (NK) cells: An important NK cell subset. Immunology 2009, 126, 458-465. [CrossRef] [PubMed]

8. Fehniger, T.A.; Caligiuri, M.A. Interleukin 15: Biology and relevance to human disease. Blood 2001, 97, 14-32. [CrossRef] [PubMed]

9. Fehniger, T.A.; Cooper, M.A.; Caligiuri, M.A. Interleukin-2 and interleukin-15: Immunotherapy for cancer. Cytokine Growth Factor Rev. 2002, 13, 169-183. [CrossRef]

10. Zhu, S.; Phatarpekar, P.V.; Denman, C.J.; Senyukov, V.V.; Somanchi, S.S.; Nguyen-Jackson, H.T.; Mace, E.M.; Freeman, A.F.; Watowich, S.S.; Orange, J.S.; et al. Transcription of the activating receptor nkg2d in natural killer cells is regulated by stat3 tyrosine phosphorylation. Blood 2014, 124, 403-411. [CrossRef] [PubMed]

11. Denman, C.; Senyukov, V.; Somanchi, S.; Phatarpekar, P.; Kopp, L.; Johnson, J.; Singh, H.; Hurton, L.; Maiti, S.; Huls, M.; et al. Membrane-bound il-21 promotes sustained ex vivo proliferation of human natural killer cells. PLoS ONE 2012, 7, e30264. [CrossRef] [PubMed]

12. Romee, R.; Rosario, M.; Berrien-Elliott, M.M.; Wagner, J.A.; Jewell, B.A.; Schappe, T.; Leong, J.W.; Abdel-Latif, S.; Schneider, S.E.; Willey, S.; et al. Cytokine-induced memory-like natural killer cells exhibit enhanced responses against myeloid leukemia. Sci. Transl. Med. 2016, 8, e357. [CrossRef] [PubMed]

13. Sarhan, D.; Hippen, K.L.; Lemire, A.; Hying, S.; Luo, X.; Lenvik, T.; Curtsinger, J.; Davis, Z.; Zhang, B.; Cooley, S.; et al. Adaptive NK cells resist regulatory t-cell suppression driven by il37. Cancer Immunol. Res. 2018, 6, 766-775. [CrossRef] [PubMed]

14. Pickup, M.; Novitskiy, S.; Moses, H.L. The roles of tgfbeta in the tumour microenvironment. Nat. Rev. Cancer 2013, 13, 788-799. [CrossRef] [PubMed]

15. Friedman, E.; Gold, L.I.; Klimstra, D.; Zeng, Z.S.; Winawer, S.; Cohen, A. High levels of transforming growth factor beta 1 correlate with disease progression in human colon cancer. Cancer Epidemiol. Biomark. Prev. 1995, 4, 549-554.

16. Yang, R.S.; Wu, C.T.; Lin, K.H.; Hong, R.L.; Liu, T.K.; Lin, K.S. Relation between histological intensity of transforming growth factor-beta isoforms in human osteosarcoma and the rate of lung metastasis. Tohoku J. Exp. Med. 1998, 184, 133-142. [CrossRef] [PubMed]

17. Picon, A.; Gold, L.I.; Wang, J.; Cohen, A.; Friedman, E. A subset of metastatic human colon cancers expresses elevated levels of transforming growth factor beta1. Cancer Epidemiol. Biomark. Prev. 1998, 7, 497-504.

18. Trotta, R.; Dal Col, J.; Yu, J.; Ciarlariello, D.; Thomas, B.; Zhang, X.; Allard, J., 2nd; Wei, M.; Mao, H.; Byrd, J.C.; et al. Tgf-beta utilizes smad3 to inhibit cd16-mediated ifn-gamma production and antibody-dependent cellular cytotoxicity in human NK cells. J. Immunol. 2008, 181, 3784-3792. [CrossRef] [PubMed] 
19. Yu, J.; Wei, M.; Becknell, B.; Trotta, R.; Liu, S.; Boyd, Z.; Jaung, M.S.; Blaser, B.W.; Sun, J.; Benson, D.M., Jr.; et al. Pro- and antiinflammatory cytokine signaling: Reciprocal antagonism regulates interferon-gamma production by human natural killer cells. Immunity 2006, 24, 575-590. [CrossRef] [PubMed]

20. Tang, P.M.; Zhou, S.; Meng, X.M.; Wang, Q.M.; Li, C.J.; Lian, G.Y.; Huang, X.R.; Tang, Y.J.; Guan, X.Y.; Yan, B.P.; et al. Smad3 promotes cancer progression by inhibiting e4bp4-mediated NK cell development. Nat. Commun. 2017, 8, e14677. [CrossRef] [PubMed]

21. Bellone, G.; Aste-Amezaga, M.; Trinchieri, G.; Rodeck, U. Regulation of NK cell functions by tgf-beta 1. J. Immunol. 1995, 155, 1066-1073. [PubMed]

22. Donatelli, S.S.; Zhou, J.M.; Gilvary, D.L.; Eksioglu, E.A.; Chen, X.; Cress, W.D.; Haura, E.B.; Schabath, M.B.; Coppola, D.; Wei, S.; et al. Tgf-beta-inducible microrna-183 silences tumor-associated natural killer cells. Proc. Natl. Acad. Sci. USA 2014, 111, 4203-4208. [CrossRef] [PubMed]

23. Keskin, D.B.; Allan, D.S.; Rybalov, B.; Andzelm, M.M.; Stern, J.N.; Kopcow, H.D.; Koopman, L.A.; Strominger, J.L. Tgfbeta promotes conversion of cd16+ peripheral blood NK cells into cd16- NK cells with similarities to decidual NK cells. Proc. Natl. Acad. Sci. USA 2007, 104, 3378-3383. [CrossRef] [PubMed]

24. Lee, J.C.; Lee, K.M.; Kim, D.W.; Heo, D.S. Elevated tgf-beta1 secretion and down-modulation of nkg2d underlies impaired NK cytotoxicity in cancer patients. J. Immunol. 2004, 172, 7335-7340. [CrossRef] [PubMed]

25. Tran, H.C.; Wan, Z.; Sheard, M.A.; Sun, J.; Jackson, J.R.; Malvar, J.; Xu, Y.; Wang, L.; Sposto, R.; Kim, E.S.; et al. Tgfbetar1 blockade with galunisertib (ly2157299) enhances anti-neuroblastoma activity of the anti-gd2 antibody dinutuximab (ch14.18) with natural killer cells. Clin. Cancer Res. 2017, 23, 804-813. [CrossRef] [PubMed]

26. Wilson, E.B.; El-Jawhari, J.J.; Neilson, A.L.; Hall, G.D.; Melcher, A.A.; Meade, J.L.; Cook, G.P. Human tumour immune evasion via tgf-beta blocks NK cell activation but not survival allowing therapeutic restoration of anti-tumour activity. PLoS ONE 2011, 6, e22842. [CrossRef] [PubMed]

27. Xu, Y.; Sun, J.; Sheard, M.A.; Tran, H.C.; Wan, Z.; Liu, W.Y.; Asgharzadeh, S.; Sposto, R.; Wu, H.W.; Seeger, R.C. Lenalidomide overcomes suppression of human natural killer cell anti-tumor functions by neuroblastoma microenvironment-associated il-6 and tgfbeta1. Cancer Immunol. Immunother CII 2013, 62, 1637-1648. [CrossRef] [PubMed]

28. Castriconi, R.; Cantoni, C.; Della Chiesa, M.; Vitale, M.; Marcenaro, E.; Conte, R.; Biassoni, R.; Bottino, C.; Moretta, L.; Moretta, A. Transforming growth factor beta 1 inhibits expression of nkp30 and nkg2d receptors: Consequences for the NK-mediated killing of dendritic cells. Proc. Natl. Acad. Sci. USA 2003, 100, 4120-4125. [CrossRef] [PubMed]

29. Park, Y.P.; Choi, S.C.; Kiesler, P.; Gil-Krzewska, A.; Borrego, F.; Weck, J.; Krzewski, K.; Coligan, J.E. Complex regulation of human $\mathrm{nkg} 2 \mathrm{~d}$-dap10 cell surface expression: Opposing roles of the gammac cytokines and tgf-beta1. Blood 2011, 118, 3019-3027. [CrossRef] [PubMed]

30. Fujii, R.; Jochems, C.; Tritsch, S.R.; Wong, H.C.; Schlom, J.; Hodge, J.W. An il-15 superagonist/il-15ralpha fusion complex protects and rescues NK cell-cytotoxic function from tgf-beta1-mediated immunosuppression. Cancer Immunol. Immunother CII 2018, 67, 675-689. [CrossRef] [PubMed]

31. Otegbeye, F.; Ojo, E.; Moreton, S.; Mackowski, N.; Lee, D.A.; de Lima, M.; Wald, D.N. Inhibiting tgf-beta signaling preserves the function of highly activated, in vitro expanded natural killer cells in aml and colon cancer models. PLoS ONE 2018, 13, e0191358.

32. Allan, D.S.; Rybalov, B.; Awong, G.; Zuniga-Pflucker, J.C.; Kopcow, H.D.; Carlyle, J.R.; Strominger, J.L. Tgf-beta affects development and differentiation of human natural killer cell subsets. Eur. J. Immunol. 2010, 40, 2289-2295. [CrossRef] [PubMed]

33. Cortez, V.S.; Ulland, T.K.; Cervantes-Barragan, L.; Bando, J.K.; Robinette, M.L.; Wang, Q.; White, A.J.; Gilfillan, S.; Cella, M.; Colonna, M. Smad4 impedes the conversion of NK cells into ilc1-like cells by curtailing non-canonical tgf-beta signaling. Nat. Immunol. 2017, 18, 995-1003. [PubMed]

34. Cortez, V.S.; Cervantes-Barragan, L.; Robinette, M.L.; Bando, J.K.; Wang, Y.; Geiger, T.L.; Gilfillan, S.; Fuchs, A.; Vivier, E.; Sun, J.C.; et al. Transforming growth factor-beta signaling guides the differentiation of innate lymphoid cells in salivary glands. Immunity 2016, 44, 1127-1139. [CrossRef] [PubMed]

35. Gao, Y.; Souza-Fonseca-Guimaraes, F.; Bald, T.; Ng, S.S.; Young, A.; Ngiow, S.F.; Rautela, J.; Straube, J.; Waddell, N.; Blake, S.J.; et al. Tumor immunoevasion by the conversion of effector NK cells into type 1 innate lymphoid cells. Nat. Immunol. 2017, 18, 1004-1015. [CrossRef] [PubMed] 
36. Gasteiger, G.; Hemmers, S.; Firth, M.A.; Le Floc'h, A.; Huse, M.; Sun, J.C.; Rudensky, A.Y. Il-2-dependent tuning of NK cell sensitivity for target cells is controlled by regulatory $t$ cells. J. Exp. Med. 2013, 210, 1167-1178. [CrossRef] [PubMed]

37. McKarns, S.C.; Schwartz, R.H. Distinct effects of tgf-beta 1 on cd4+ and cd8+ t cell survival, division, and il-2 production: A role for $\mathrm{t}$ cell intrinsic smad3. J. Immunol. 2005, 174, 2071-2083. [CrossRef] [PubMed]

38. Dahmani, A.; Delisle, J.S. Tgf-beta in t cell biology: Implications for cancer immunotherapy. Cancers 2018, 10, 194. [CrossRef] [PubMed]

39. Gwalani, L.A.; Orange, J.S. Single degranulations in NK cells can mediate target cell killing. J. Immunol. 2018, 200, 3231-3243. [CrossRef] [PubMed]

40. Samten, B.; Townsend, J.C.; Weis, S.E.; Bhoumik, A.; Klucar, P.; Shams, H.; Barnes, P.F. Creb, atf, and ap-1 transcription factors regulate ifn-gamma secretion by human $t$ cells in response to mycobacterial antigen. J. Immunol. 2008, 181, 2056-2064. [CrossRef] [PubMed]

41. Penix, L.A.; Sweetser, M.T.; Weaver, W.M.; Hoeffler, J.P.; Kerppola, T.K.; Wilson, C.B. The proximal regulatory element of the interferon-gamma promoter mediates selective expression in t cells. J. Biol. Chem. 1996, 271, 31964-31972. [CrossRef] [PubMed]

42. Lougaris, V.; Patrizi, O.; Baronio, M.; Tabellini, G.; Tampella, G.; Damiati, E.; Frede, N.; van der Meer, J.W.M.; Fliegauf, M.; Grimbacher, B.; et al. Nfkb1 regulates human NK cell maturation and effector functions. Clin. Immunol. 2017, 175, 99-108. [CrossRef] [PubMed]

43. Dai, C.; Krantz, S.B. Interferon gamma induces upregulation and activation of caspases 1, 3, and 8 to produce apoptosis in human erythroid progenitor cells. Blood 1999, 93, 3309-3316. [PubMed]

44. Inaba, H.; Glibetic, M.; Buck, S.; Ravindranath, Y.; Kaplan, J. Interferon-gamma sensitizes osteosarcoma cells to fas-induced apoptosis by up-regulating fas receptors and caspase-8. Pediatr. Blood Cancer 2004, 43, 729-736. [CrossRef] [PubMed]

45. Meister, N.; Shalaby, T.; von Bueren, A.O.; Rivera, P.; Patti, R.; Oehler, C.; Pruschy, M.; Grotzer, M.A. Interferon-gamma mediated up-regulation of caspase-8 sensitizes medulloblastoma cells to radio- and chemotherapy. Eur. J. Cancer 2007, 43, 1833-1841. [CrossRef] [PubMed]

46. Li, Z.; Xu, Q.; Peng, H.; Cheng, R.; Sun, Z.; Ye, Z. Ifn-gamma enhances hos and u2os cell lines susceptibility to gammadelta t cell-mediated killing through the fas/fas ligand pathway. Int. Immunopharmacol. 2011, 11, 496-503. [CrossRef] [PubMed]

47. Wang, R.; Jaw, J.J.; Stutzman, N.C.; Zou, Z.; Sun, P.D. Natural killer cell-produced ifn-gamma and tnf-alpha induce target cell cytolysis through up-regulation of icam-1. J. Leukoc. Biol. 2012, 91, 299-309. [CrossRef] [PubMed]

48. Smyth, M.J.; Cretney, E.; Takeda, K.; Wiltrout, R.H.; Sedger, L.M.; Kayagaki, N.; Yagita, H.; Okumura, K. Tumor necrosis factor-related apoptosis-inducing ligand (trail) contributes to interferon gamma-dependent natural killer cell protection from tumor metastasis. J. Exp. Med. 2001, 193, 661-670. [CrossRef] [PubMed]

49. Screpanti, V.; Wallin, R.P.; Grandien, A.; Ljunggren, H.G. Impact of fasl-induced apoptosis in the elimination of tumor cells by NK cells. Mol. Immunol. 2005, 42, 495-499. [CrossRef] [PubMed]

50. Screpanti, V.; Wallin, R.P.; Ljunggren, H.G.; Grandien, A. A central role for death receptor-mediated apoptosis in the rejection of tumors by NK cells. J. Immunol. 2001, 167, 2068-2073. [CrossRef] [PubMed]

51. Somanchi, S.S.; Senyukov, V.V.; Denman, C.J.; Lee, D.A. Expansion, purification, and functional assessment of human peripheral blood NK cells. J. Vis. Exp. 2011, 48, e2540. [CrossRef] [PubMed]

52. Buenrostro, J.D.; Giresi, P.G.; Zaba, L.C.; Chang, H.Y.; Greenleaf, W.J. Transposition of native chromatin for fast and sensitive epigenomic profiling of open chromatin, DNA-binding proteins and nucleosome position. Nat. Methods 2013, 10, 1213-1218. [CrossRef] [PubMed]

53. Metsalu, T.; Vilo, J. Clustvis: A web tool for visualizing clustering of multivariate data using principal component analysis and heatmap. Nucleic Acids Res. 2015, 43, W566-W570. [CrossRef] [PubMed]

(C) 2018 by the authors. Licensee MDPI, Basel, Switzerland. This article is an open access article distributed under the terms and conditions of the Creative Commons Attribution (CC BY) license (http:/ / creativecommons.org/licenses/by/4.0/). 